\title{
Understanding Intention to Use Multimedia Information Systems for Learning
}

\author{
Raafat George Saadé, Ian Galloway \\ John Molson School of Business, Concordia University \\ Montreal, Quebec, Canada
}

rsinfo@sympatico.ca igalloway@jmsb.concordia.ca

\begin{abstract}
The challenge today for educators interested in online teaching and learning is how to create, use and assess multimedia technologies for enhanced learning. Unlike hypertext and web-based instruction, the reliance on reading blocks of text is minimized. There still remains little evidence supporting multimedia to enhance learning. From the author's perspectives, the challenge is to better understand the processes involved in developing effective multimedia tools and to establish appropriate assessment methodologies that may be used to guide standards and 'good educational multimedia design practice'. This paper aims at sharing the author's experiences with the development of a multimedia tool and its assessment. A multimedia learning system (MMLS) is presented and the Technology Acceptance Model (TAM) is used to explain user acceptance. We investigate and discuss the TAM results involving a different technology used in a different context. As an initial attempt to understand students' beliefs, perceptions, attitudes and intentions (and their inter-relationships) our results show that TAM performs well in explaining them.
\end{abstract}

Keywords: Multimedia, TAM, Information Technology, e Learning

\section{Introduction}

Throughout the past decade the developed world saw a boom of the Internet driven by the rapid advancement of computer technologies and the resulting information systems (IS) (Saadé \& Bahli, 2005). The management of these IS aims at applying these associated vast information resources successfully. In order to successfully manage these IS we must match the correct processes with the appropriate technologies and applications. An important step towards that is the studying of factors determining the appropriateness of a systems' usage (Koohand \& Durante, 2003).

In this study we present our experiences with a multimedia tool. Generally, multimedia applications are considered to be computer applications that allow users to interact with audio and video to convey information (Gonzalez, 2000). This definition has been modified many times. The common features that are held between most definitions are that information is accessed and controlled using more than one mode of data representation. (Low, 2003; MacDonald, 2003). These different modes include pictures, text, animations, audio, and video. Multimedia learning systems

Material published as part of this journal, either on-line or in print, is copyrighted by Informing Science. Permission to make digital or paper copy of part or all of these works for personal or classroom use is granted without fee provided that the copies are not made or distributed for profit or commercial advantage AND that copies 1) bear this notice in full and 2) give the full citation on the first page. It is permissible to abstract these works so long as credit is given. To copy in all other cases or to republish or to post on a server or to redistribute to lists requires specific permission from the publisher at Publisher@InformingScience.org have been heralded as providing benefits both to students and administrators alike (Marold, 2002). Benefits to administrators are usually measured in terms of savings (time and money) when managing resources. Often benefits affect both groups of users such as gains in temporal and geo- 
graphical availability (Manning, 2003). Multimedia tools capitalize on the student's needs by offering more interactivity in online learning modules (Chen, 2004). Multimedia learning tools can be developed to perform simulations or play games at the same time as provide presentations. These styles of tools offer instantaneous feedback (Saade, 2003). This interactivity increases the student's belief that they are in control of their learning activity (Lainema, 2004). Enhancing the learning tools in this way helps to bring a higher sense of connectivity between the students and the program. The objective of developing and using a multimedia tool in an online educational setting promotes students to be less passive in their learning experience.

The increase in information technology infrastructure has led to many changes throughout society and particularly within the education industry. Some of these changes entail multimedia use in human computer interfaces, increasing multimedia and information technology use for entertainment, increased use of information technology for communication and increased use of ebusiness (Hsu, 2004; Liu, 2003). Online multimedia learning has resulted from all of these factors and is seen to be the replacement to all forms of distance education (Liu, 2003). Research done on online multimedia learning has mainly focused at determining how to use tools to get the most affect on final learning. Researchers have broken down user groups by demographics in order to customize learning tools (Liu, 2003), concept mapping has continued to breakdown user guidance needs (Lin, 2004), and have gauged self-efficacy and satisfaction as measures of success for the tools (Cheung, 2003; Wang, 2003). All of these methods have lead to a better understanding of how to create multimedia learning tools.

It has also been noted within these studies that the more users utilize the system the greater the success they will have learning the material (Hwang, 2003). In general we are performing this study to understand acceptance of online multimedia IS to be used for database modeling. Multimedia tools capitalize on the students need for more interactivity, which has shown to aid the student's beliefs of enhanced learning (Hill, 2004). To that effect, the goal of this paper is to study intention to use multimedia learning systems (MMLS).

\section{Research Objective}

In this study we are concerned with online learning using a MMLS. Based on our literature review computers have been used to teach many different types of content with varying degrees of success (Sunal, Sunal, Odell, \& Sundberg, 2003). Our intention is to measure variables affecting the acceptance of multimedia learning tools and, to a greater extent, understand how user's perceptions can be used to improve student's online learning through multimedia. Specifically the study of the MMLS developed in this study has the following objectives:

- To validate the use of the Technology Acceptance Model (TAM) for understanding intention to use multimedia educational tools for learning.

- To investigate the role of attitudes toward a multimedia learning system on intention to use.

- To present our experiences with the design and use of a multimedia information systems for learning.

\section{Research Model}

This study is based on the Technology Acceptance Model, TAM (Davis, 1989). TAM is a renowned method for testing the acceptance of an IS. In this study the TAM was used due to the focus on measuring the perceived usefulness (PU) of the MMLS which clearly should play a large part in the users' decision to adopt or intentions to use the MMLS. PU can be interpreted as the performance benefit that the student believes he/she will receive for using the MMLS. The 
other main construct in the original TAM is perceived ease of use PEU. This factor is representative of the student's beliefs towards the amount of effort that is required to use the tool. Attitude in TAM can be described as the users emotional/affect connection to MMLS. Finally the intention to use is considered to be a direct predictor of future system use. In this case this intention to use would be toward other similar multimedia learning systems used as part of online courses.

Although, attitude was dropped from the original TAM because of its weak influence in mediating PU and PEU on intentions to use, we however kept it in our model for two reasons: firstly the difference in the context and in the students' motivation to use the MMLS and secondly due to the characteristics associated with online learning (Davis, 1989). The difference in motivation to use the MMLS is due to the context which the IS (in this case the MMLS) is being used. In the present context of higher education, some students might not believe that using the MMLS or any other computer-aided tool is the most effective way to learn; consequently students may not even use the tool at all. Unlike the normal TAM which is designed to represent the intention to use in a work environment where users have no choice but to use the system on a daily basis and influenced by their boss, students have the option to choose which educational tools to use and how much to use them.

Students' complaints to online learning about delay in response, lack of trust in the expertise of peers and most importantly a lack of connection with classmates and educators have been reported (Hill, 2004). These characteristics can create a negative attitude toward the online system being used. Recent papers have also found that attitude can play an important role in affecting users' intention to use (Yang, 2003). Attitude is the users beliefs towards the systems' characteristics as being beneficial or deterrent. In light of these studies, we felt that attitude should be included.

Since factors affecting user acceptance are many and often vary depending on the characteristics of the IS used and the context it is used in, it is reasonable to validate the original TAM. Based on the latter discussion, we hypothesize that

H1. Attitude will have a positive relationship with Intention to Use.

H2. Perceived Usefulness will have a positive relationship with Intention to Use.

H3. Perceived Ease of Use will have a positive relationship with Attitude

H4. Perceived Usefulness will have a positive relationship with Attitude.

H5. Perceived Ease of Use will have a positive relationship with Perceived Usefulness.

The proposed model is shown in Figure 1.

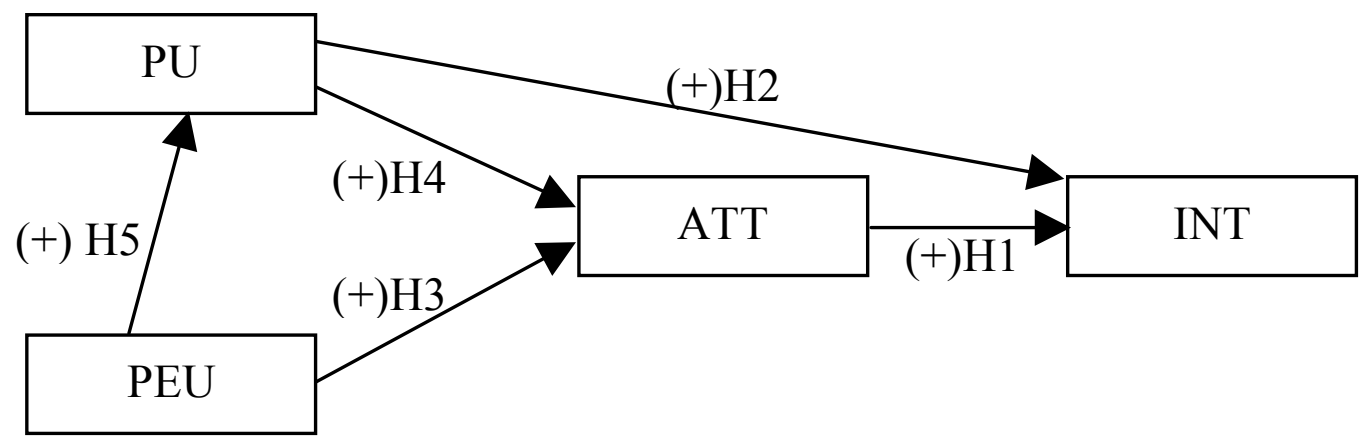

Figure 1: The Proposed Model 


\section{The Multimedia Information System}

The MMLS is a web- based learning tool accessed via the web browser. The purpose of the MMLS is to give students a multimedia resource to learn the concepts of entity relationship diagrams (ERDs) as part of an undergraduate management information systems course and practice making ERD's in an interactive medium. The MMLS uses Entity Relationship and flowchart symbols to logically represent the relationships of entities within a database. The operation of the MMLS is similar to that of CASE tools. The user is given a whiteboard for workspace and access to multiple ERD symbols. As shown in Figure 2, the interface is made up of four regions/panels. The top panel presents a statement of the problem. The bottom panel includes an icon-based menu that entails the features of the MMLS. The right panel contains the symbols required to solve the problem and the large region in the center is the working area. The symbols given are in the exact amount and style required to complete the given problem. The symbols provided are entities, relationships and cardinalities (many and one). Using the MMLS the user must place the correct ER symbol in the correct relationship order. In this fashion the MMLS is similar to a puzzle game online, where the ERD symbols are the pieces. The entity specifications used in each problem are supplied by a case given to the user at the beginning of each session. There is only one fully correct answer to each case but there are multiple ways of solving each case depending on the case.

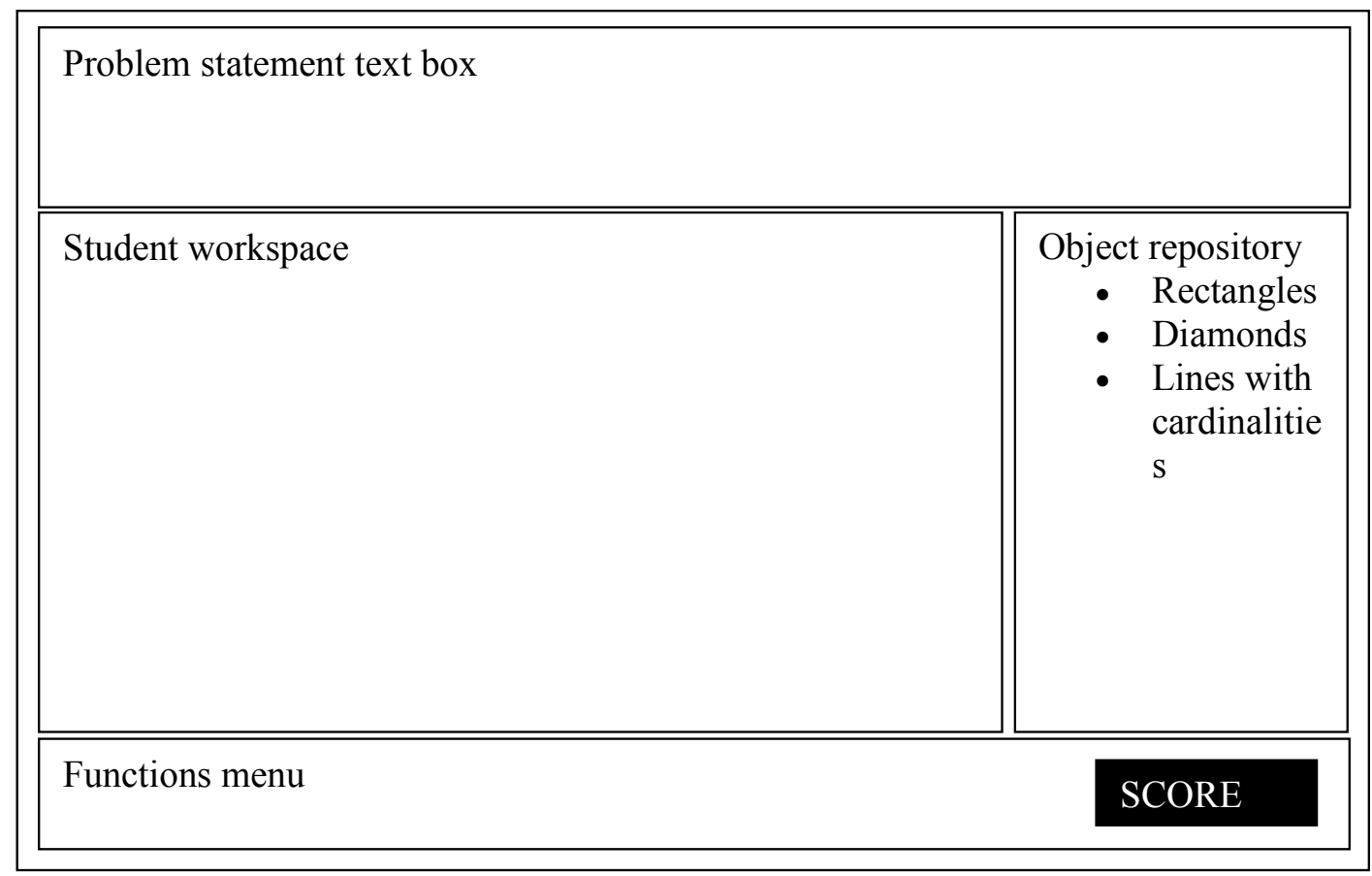

Figure 2: Layout of Multimedia Interface

To access the MMLS a student would log on to a server hosting the classes' material and is presented with varying study materials and methods. These range from online quizzes and power point presentations to a class forum. After selecting the MMLS link the student is given the option to view an animated presentation that explains ERD concepts. In the practicing problem area of the MMLS, the student is presented with a case that describes the business situation and the database needs. The student then drags one symbol at a time from the object repository panel and drops it in the workspace. This panel is blank at the beginning of the problem. Movement of symbols is permitted at all times within the workspace. If the student places the wrong entity 
symbol with the wrong relationship symbol the symbol being used is returned to the object repository and 10 points are removed from the total of 100 .

When a score reaches 70, the student is then given the option to view a hint. If the students score drops to 50 or below, then the student gets the option to have the MMLS present a step-by-step animated presentation of how to solve the problem. At any point during the session the student can view a help sheet, return to the main page or to scroll through other questions. Upon completion of the correct ERD the student is congratulated and given an option to continue with another ERD problem or to return to the main page.

\section{Methodology}

Data for this study was collected via a questionnaire administered by the professor at the end of the course. The 13 items in the questionnaire (given in the appendix) were measured using a fivepoint Likert-type scale with anchors from "Strongly agree" to "Strongly disagree".

The study included samples from two successive semesters with students taking the same course delivered by the same professor with the same characteristics. The collection of these questionnaires yielded 128 usable data responses.

The students who completed the questionnaires did so voluntarily with no reimbursement for their participation. Their use of the MMLS was motivated by the desire to practice ERD problem solving with the perception of better performance on this part of the examination. The students who filled out the questionnaire were taking a core management information systems course at Concordia University in Montreal, Canada. This class is a 300 level commerce core class.

A structural equation modeling (SEM) approach was followed for the analysis of data using PLS graph software. Using this software is a norm within the IS academic community. PLS graph was developed by Dr. Chin at the University of Houston. This software calculates the common factor analysis as one system. In other words the correlation between all factors is calculated with relation to each other. PLS graph also performs confirmatory factor analysis (Chin, 1998). Many businesses and arts fields have found such an approach useful and this method of solution is increasing in popularity within academia (Hsu, 2004).

\section{Discussion and Analysis of Results}

Table 1 displays the descriptive statistics. Included in this table are the number of variables used for each factor and the calculation of Rho. Rho was calculated to assess the reliability of the latent variables. As shown in Table 1 the calculation of Rho for each of the factors used is significantly greater than the acceptable limit of 0.5 .

Table 1: Descriptive Statistics

\begin{tabular}{|l|c|c|c|c|}
\hline Variables & \# of items & Rho & Mean & SD \\
\hline Perceived Usefulness (PU) & 4 & 0.947 & 3.5 & 0.946 \\
\hline Perceived Ease of Use (PEU) & 4 & 0.964 & 3.5 & 1.085 \\
\hline Attitude (ATT) & 3 & 0.897 & 3.5 & 0.926 \\
\hline Intention to Use (INT) & 2 & 0.921 & 4.0 & 1.044 \\
\hline
\end{tabular}

The results of factor analysis are presented in Table 2. Varimax rotation was used to determine the individual factor loading and eigenvalues. The varimax rotation was performed to ensure that all variables were more closely related to their expected factor than to any other factor. This is 
proven by checking that the sets of variables load greater on their intended factor than on any other factor. All four factors displayed eigenvalues greater than 1 and without exception all variables loaded on their factors. Reliabilities of individual items were assessed by examining the loadings of the items on their respective constructs. These loadings should be higher than 0.5 , following the criterion indicated by (Rivard, 1993) to indicate that significant variance was shared between each item and the construct. The results of the factor analysis show that all variables matched their correlating variables and that there are no problems with the convergent and discriminate validity of the data sets.

Table 2: Varimax Rotation Results

\begin{tabular}{|c|c|c|c|c|}
\hline & PEU & ATT & PU & INT \\
\hline PEU1 & $\mathbf{0 . 7 2 0}$ & 0.181 & 0.224 & 0.123 \\
\hline PEU2 & $\mathbf{0 . 7 0 6}$ & 0.079 & 0.178 & 0.081 \\
\hline PEU3 & $\mathbf{0 . 6 7 9}$ & 0.058 & 0.164 & 0.129 \\
\hline PEU4 & $\mathbf{0 . 8 2 8}$ & 0.064 & 0.194 & 0.174 \\
\hline PU1 & 0.185 & 0.200 & $\mathbf{0 . 7 2 9}$ & 0.117 \\
\hline PU2 & 0.122 & 0.171 & $\mathbf{0 . 8 2 8}$ & 0.145 \\
\hline PU3 & 0.206 & 0.128 & $\mathbf{0 . 8 0 2}$ & 0.112 \\
\hline PU4 & 0.342 & 0.277 & $\mathbf{0 . 6 3 0}$ & 0.320 \\
\hline ATT1 & 0.050 & $\mathbf{0 . 8 6 3}$ & 0.178 & 0.227 \\
\hline ATT2 & 0.097 & $\mathbf{0 . 8 4 4}$ & 0.143 & 0.232 \\
\hline ATT3 & 0.087 & $\mathbf{0 . 9 3 2}$ & 0.131 & 0.201 \\
\hline INT1 & 0.121 & 0.366 & 0.159 & $\mathbf{0 . 9 1 1}$ \\
\hline INT2 & 0.217 & 0.284 & 0.191 & $\mathbf{0 . 6 9 2}$ \\
\hline
\end{tabular}

The Average Variance Extracted (AVE) is displayed in Table 3. These calculations further prove the convergent and discriminant validities. Cells on the diagonal are the results of the AVE square roots and the off diagonals are the results of the squared correlations. As suggested the results on the diagonal are greater than those on the off diagonals.

Table 3: Variance Shared Between Constructs.

\begin{tabular}{|c|c|c|c|c|}
\hline & Variance & & & \\
\hline Variables & PU & PEU & ATT & INT \\
\hline PU & $\mathbf{0 . 8 6 3}$ & & & \\
\hline PEU & 0.487 & $\mathbf{0 . 8 2 8}$ & & \\
\hline ATT & 0.425 & 0.251 & $\mathbf{0 . 9 4 8}$ & \\
\hline INT & 0.427 & 0.366 & 0.536 & $\mathbf{0 . 9 4 6}$ \\
\hline
\end{tabular}

PLS-Graph was used to complete the SEM and to calculate the R-squared values and Path coefficients. All hypothesis' tested were shown to have valid positive relationships except for that of perceived ease of use to attitude toward the MMLS. 
In Figure 3 the path coefficients are displayed above their respective relationships. All path coefficients have a $\mathrm{p}$-value $<0.01$. The explained variance of intention to use provide by this model was $38.3 \%$. The strongest contributor to this was attitude toward system (path $=.442)$. Perceived usefulness the other direct influencer of intention to use had a weaker but still acceptable path coefficient (path $=.284$ ). Attitude toward system was positively influenced by perceived usefulness (path $=.396$ ) but attitude was not significantly affected by perceived ease of use. The path coefficient between PEU and ATT was found to be not significant (path =.059). The explained variance of attitude factor is $18.3 \%$. This relationship is valid due to the relationship having a $\mathrm{p}$ value $<.005$. The percentage of variance explained for PU is 23.7 .

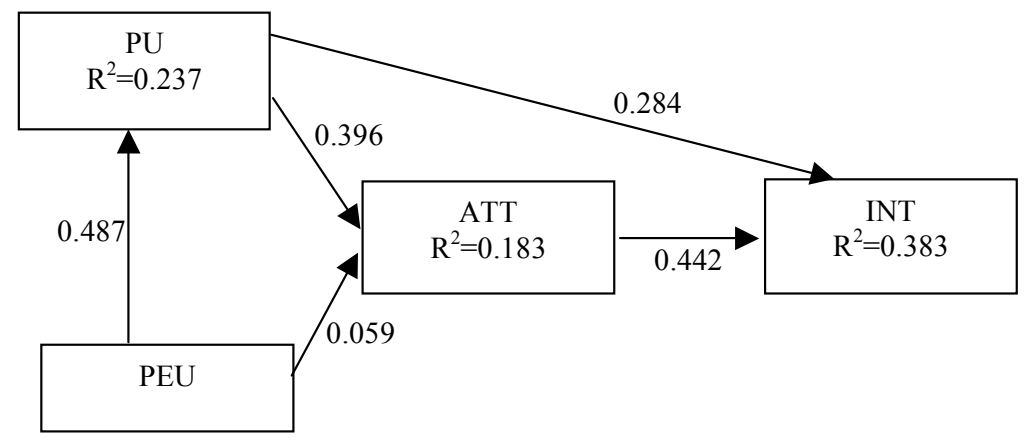

Figure 3: The PLS Model Results

\section{Conclusion}

In this study the students did find the MMLS easy to use, useful and students had a good attitude toward using the MMLS. Analysis of the questionnaire results demonstrated the viability of the TAM model for use with multimedia learning tools to understand acceptance of the MMLS. The model chosen predicted a significant amount of the variance determining user intention. The ability of the TAM to predict user intention with such varying applications is a testament to the design of the model. The success of this model implies that some of the factors related to user acceptance of online educational tools are those incorporated in the TAM with the addition of attitude.

As with any study the present study is not without its own weaknesses and strengths. Among the weakness of this study is the fact that the feelings, beliefs and attitudes about the tool cannot be directly recorded and interpreted and must be analyzed with the use of a questionnaire. This method causes inaccuracies because the answers recorded can be affected by the participants' subjectivity. Since the questionnaires were not completed at the same time, this method also suffers from temporal effects. Questionnaires are only capable of measuring the user at a certain point of time and not through out their experiences or when the user is presented with another similar tool. The specific use of the MMLS to practice design of ERDs also limited the user's value of the system depending on the importance individual students placed on ERDs in preparing for their final exam and the varying amount of representation of ERDs in the two differing final exams.

Unlike many studies where students are questioned on an application that is intended for business or daily operation purposes in a work environment, this study uses students to measure an application designed for student's learning. Therefore there is a better fit between the purpose of the tool and the study context. The strength of this study is the specificity of the study to the type of tool. Since this study only attempts to reflect the intention to use multimedia based online learning tools it does not suffer from the broadness of most TAM studies. In other words this study using TAM is more specific. There is no guarantee that although the TAM can be used to ap- 
proximate the acceptance of a tested word processing tool that the same model of the TAM is equally appropriate for accounting software.

Further research will have to be done to discover how to extenuate what we have learned in this study to improve online learning via multimedia tools.

\section{References}

Hwang, W., Hsu, R. \& Chen, N (2004). Development and evaluation of multimedia whiteboard system fro improving mathematical problem solving. Computers and Education, in press.

Cheung, W., Li, E. \&Yee, L. (2003). Multimedia learning system and its effect on self-efficacy in database modeling and design: an exploratory study. Computers and Education, 41, 249-270.

Chin, W. (1998). Issues and opinions on structural equation modeling. Management Information Systems Quarterly, 22.

Davis, F.D. (1989). Perceived Usefulness, perceived ease of use, and user acceptance of information technology. Management Information Systems Quarterly, 13, 319-339.

Gonzalez, R. (2000). Disciplining multimedia. IEEE Multimedia, 7, 72-78.

Hill, J .R., Hwa Koh, M., Singleton, E .S. \& Song, L. (2004). Improving online learning: Student perceptions of useful and challenging characteristics. The Internet and Higher Education, 7, 59-70.

Hsu, C. \& Lu, H. (2004). Why do people play on-line games? An extended TAM with Social influences and flow experience. Information and Management, 41, 853-868.

Hwang, Y. \& Yi, M., (2003). Predicting the use of web-based information systems: Self-efficacy, enjoyment, learning goal orientation, and the technology acceptance model. International Journal of Human-Computer Studies, 59, 431-449.

Koohang, A. \& Durante, A. (2003). Learners' perceptions toward the web-based distance learning activities/assignments portion of an undergraduate hybrid instructional model. Journal of Information Technology Education, 2, 105-113.

Lianema, T. (2004). Redesigning the traditional business gaming process - Aiming to capture business process authenticity. Journal of Information Technology Education, 3, 35-52.

Lin, D. (2004). Evaluating older adults' retention in hypertext perusal: Impacts of presentation media as a function of text topology. Computers in Human Behavior, 20, 491-503.

Liu, C., Lu, J. \&Yu, C. (2003). Learning style, learning patterns, and learning performance in a WebCTbased MIS course. Information and Management, 40, 497-507.

Low, A., Low, K. \& Koo, V. (2003). Multimedia learning systems: A future interactive educational tool. The Internet and Higher Education, 6, 25-40

Manning, R., Cohen, M. \& DeMichiell, R. (2003). Distance learning: Step by step. Journal of Information Technology Education, 2, 115-130.

Marold, K. (2002). The $21^{\text {st }}$ century learning model: Electronic tutelage realized, Journal of Information Technology Education, 1 (2), 113-124.

McDonald, D. (2004). The influence of multimedia training on users' attitudes lessons learned. Computes and Education, 42, 195-214

Rivard, S. (1988). Factors for success for end-user computing. Communications of the ACM, 31 (5), 552561.

Saade, R. (2003). Web-based educational information system for enhanced learning, EISEL: Student assessment. Journal of Information Technology Education, 2, 267-277. 
Saade, R. \& Bahli, B. (2005). The impact of cognitive absorption on perceived usefulness and perceived ease of use in on-line learning: An extension of the technology acceptance model. Information \& Management, 42 (2), 317-327.

Sunal, W. D., Sunal, S. C., Odell, R. M. \& Sundberg, A. C. (2003). Research-supported best practices for developing online learning. The Journal of Interactive Online Learning, 2 (1), 1-40.

Wang, Y. (2003). Assessment of learner satisfaction with asynchronous electric learning systems. Information and Management, 41, 75-86

Yang, H. \& Yoo, Y. (2003). It's all about attitude: revisiting the technology acceptance model. Decision Support Systems, 38 (1), 19-31.

\section{Appendix}

\begin{tabular}{|c|c|c|}
\hline Construct & Item & Measure \\
\hline \multirow{4}{*}{ Perceived Usefulness (PU) } & PU1 & Learning to navigate the MMLS is easy for me. \\
\hline & PU2 & $\begin{array}{l}\text { I find it easy to get the MMLS to do what I want it to } \\
\text { do. }\end{array}$ \\
\hline & PU3 & $\begin{array}{l}\text { It was easy for me to become skillful at using the } \\
\text { MMLS. }\end{array}$ \\
\hline & PU4 & I find the MMLS easy to use. \\
\hline \multirow[t]{4}{*}{ Perceived Ease of Use (PEU) } & PEU1 & $\begin{array}{l}\text { I feel that using the MMLS has improved my perform- } \\
\text { ance in the Comm301 course. }\end{array}$ \\
\hline & PEU2 & $\begin{array}{l}\text { Using the MMLS in the comm301 course has im- } \\
\text { proved my productivity. }\end{array}$ \\
\hline & PEU3 & $\begin{array}{l}\text { Using the MMLS has enhanced my effectiveness in the } \\
\text { comm } 301 \text { course. }\end{array}$ \\
\hline & PEU4 & I find the MMLS useful in the comm301 program. \\
\hline \multirow[t]{3}{*}{ Attitude (ATT) } & ATT1 & $\begin{array}{l}\text { Using MMLS in the Comm301 course were a good } \\
\text { idea. }\end{array}$ \\
\hline & ATT2 & Using MMLS in the Comm301 course were pleasant. \\
\hline & ATT3 & $\begin{array}{l}\text { Using MMLS were beneficial to me in the Comm301 } \\
\text { course. }\end{array}$ \\
\hline \multirow[t]{2}{*}{ Intention to Use (INT) } & INT1 & $\begin{array}{l}\text { I intend to use MMLS frequently whenever they are } \\
\text { available. }\end{array}$ \\
\hline & INT2 & $\begin{array}{l}\text { I intend to be a heavy user of MMLS whenever they } \\
\text { are available. }\end{array}$ \\
\hline
\end{tabular}




\section{Biographies}

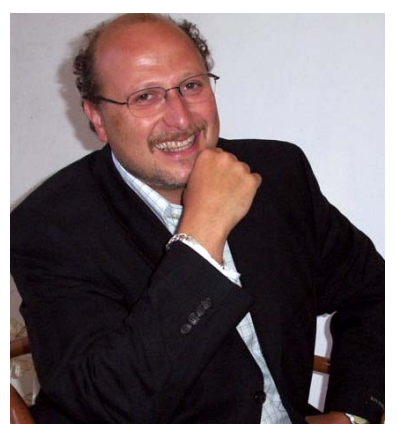

Dr. Raafat Saadé is an assistant professor at the Department of decision sciences and management information systems, John Molson School of Business, Concordia University, Montréal, Québec, Canada. After completing his Ph.D. in 1995 Dr. Saadé was awarded the national research Council Postdoctoral Fellowship which he completed at McGill University. Dr. Saadé has over 14 years of relevant industrial experience. During the past seven years, his work focused on the development and use of intelligent e-learning and e-health systems. Dr. Saadé is a founder of a non-profit organization (Viéquili-

bré/BalancedLife) targeting the health, educational and spiritual needs of seniors, for a balanced life. At present, Dr. Saadé is involved in the implementation of: (1) Osteoporosis and obesity Expert Systems, (2) a program for Senior's screening for malnutrition, (3) implementation of web-based information system for three online courses and (4) the testing of a three-tier pedagogical architecture for e-Learning. Dr. Saadé has numerous publications in top refereed journals including but not limited to Journal of Information Technology in Education, Journal of Information Systems in Education, Expert Systems with Applications, and Computers in Human Behavior.

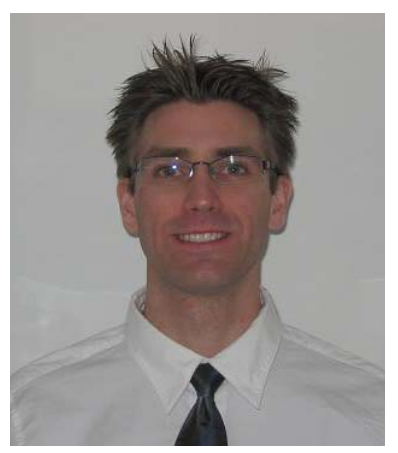

Ian Galloway is an undergraduate student in his final semester of a B.Comm program, at Concordia University. He is majoring in Management of Information Systems from the John Molson School of Business. Mr. Galloway is also a research assistant working on the assessment of multimedia effectiveness in online learning. He will continue his education in a M.Sc. in Administration. His research interests include adoption of learning systems and knowledge management. 